\title{
Thermo-physical Properties of HR3C and P92 Steels at High-temperature
}

\author{
Germain Boissonnet, Gilles Bonnet, Fernando Pedraza* \\ Laboratoire des Sciences de l'Ingénieur pour l'Environnement (LaSIE UMR-7356 CNRS), Université de La \\ Rochelle, Avenue Michel Crépeau, 17042 La Rochelle, Cedex 01, France \\ Email: fernando.pedraza@univ-Ir.fr (Corresponding author)
}

Received: 12 March 2019; Accepted: 9 May 2019; Available online: 5 August 2019

\begin{abstract}
Austenitic HR3C and ferritic-martensitic P92 steels are the materials of interest from a mechanical standpoint for the manufacturing of thermal exchangers of the next generation of steam power plants. In order to evaluate their capacity to transfer heat, thermal conductivity calculations have been conducted through the measurements of thermal diffusivity, specific heat capacity and density. It will be shown that the heat capacity, density, thermal expansion coefficient and thermal diffusivity evolve continuously with temperature in the HR3C material but not in the P92 steel. The heterogeneous thermal behaviour appears to be associated with its ferromagnetic transition rather than to the microstructural evolution. Nevertheless, the results for both steels did not exhibit significant differences between thermal conductivities at the intended temperature of service.

Keywords: Austenitic steel; Ferritic-martensitic steel; Density; Specific heat capacity; Thermal diffusivity; Thermal conductivity.
\end{abstract}

\section{Introduction}

An increase in efficiency and a reduction in greenhouse gas emissions in power generation can be achieved through advanced ultra-supercritical (A-USC) steam turbines operating at up to $760^{\circ} \mathrm{C}$ and 340 bars [1]. From a mechanical standpoint, two different steels have already been selected for their high creep strength at the temperature of interest. Ferritic-martensitic P92 was chosen for applications at up to $650^{\circ} \mathrm{C}$ and austenitic HR3C for higher temperatures [2]. As these steels are considered for heat exchangers, a good knowledge of their thermophysical properties appears as critical. However, while there are few data in the literature on the thermophysical properties of HR3C [3], those on P92 are scarce and do not cover the temperature of interest for heat exchangers [4]. A recent study showed that microstructural changes generated by different coating processes on P92 and HR3C steels could cause remarkable modifications of the thermal properties, especially for P92 steel which structure is prone to metallurgical transformations with temperature [5]. Thus, the determination of thermophysical properties of both steels (especially thermal conductivity) is crucial for heat exchange applications.

The thermal conductivity of the metallic materials at high temperature can be obtained through the measurement of thermal diffusivity by the laser flash technique [6]. Then, the thermal conductivity $\lambda$ can be calculated following equation (1):

$$
\lambda(T)=\alpha(T) \times \rho(T) \times C_{p}(T)
$$

where $\alpha$ is the thermal diffusivity measured by the laser flash technique, $\rho$ is the bulk density of the sample and $\mathrm{C}_{p}$ is the specific heat capacity [7]. In this study, calculations of the thermal conductivity have been performed using the values of $C_{p}$ and $\rho$ that have been calculated through Differential Scanning Calorimetry (DSC) for the specific heat capacity and Archimede's method combined with linear dilatometry for the density. The thermophysical data are thus reported for both steels and compared with available data.

\section{Processing and materials}

Ferritic-martensitic P92 (0.1 C, $0.5 \mathrm{Mn}, 0.03 \mathrm{Si}, 8.8 \mathrm{Cr}, 0.06 \mathrm{Ni}, 0.4 \mathrm{Mo}, 1.8 \mathrm{~W}, 0.2 \mathrm{~V}$, wt.\%, bal. Fe) and austenitic stainless HR3C (0.06 C, $1.2 \mathrm{Mn}, 0.4 \mathrm{Si}, 25.0 \mathrm{Cr}, 20.0 \mathrm{Ni}, 0.45 \mathrm{Nb}, 0.2 \mathrm{~N}$, wt.\%, bal. Fe) steels were employed as substrates (nominal compositions are given). The dimensions of P92 and HR3C samples were 10x10x2 $\mathrm{mm}^{3}$ for laser flash measurements.

The specific heat capacity of both steels was measured in a Differential Scanning Calorimeter (DSC Labsys Evo TGA SETARAM) using a 3D Cp Pt detector and by comparing to a sapphire standard. A continuous 
measurement mode was employed by heating at $10^{\circ} \mathrm{C} / \mathrm{min}$ from room temperature to $1000^{\circ} \mathrm{C}$. All the measurements were performed in flowing $\mathrm{Ar}$ and the Cp data retrieved at each temperature after at least $1500 \mathrm{~s}$ of stabilization at the temperature of interest. The density at room temperature was measured using the Archimede's method and its evolution with temperature was calculated using the results of $\Delta \mathrm{L} / \mathrm{L}_{0}$ measured via linear push-rod dilatometry by heating at $5^{\circ} \mathrm{C} / \mathrm{min}$ in air. The same measurements performed under Ar revealed no difference with the results obtained under air, proving that the impact of the oxidation of the samples during analyses was negligible. Then, thermal diffusivity of the materials was measured using the laser flash method [7] with a Linseis LFA 1600 apparatus. The thermal diffusivity measurements of the samples were conducted under vacuum from room temperature to $1000^{\circ} \mathrm{C}$. For a reasonable accuracy of the measurements, three samples were simultaneously analyzed, and the thermal diffusivity was calculated from the average of the three values. The thickness of the samples was measured with a digital caliper $10^{-3} \mathrm{~mm}$ accurate. The surfaces were all sprayed with graphite for better absorption and release of the heat flux of the laser (Nd:YAG).

The potential evolution of the microstructures with temperature vs. the as-received materials was investigated by optical microscopy (LEICA MC 170 HD) on metallographically prepared surfaces. The samples were ground with increasing grade of SiC and finally polished with diamond paste $(1 \mu \mathrm{m})$. Then, chemical (Kalling no. 2: 100 $\mathrm{mL}$ ethanol, $100 \mathrm{~mL} \mathrm{HCl}$ and $5 \mathrm{~g}$ of $\mathrm{CuCl}_{2}$ ) attacks were performed for a few seconds in both steels. Additional electrolytic etching of $\mathrm{HR} 3 \mathrm{C}$ with 10 vol\% $\mathrm{H}_{2} \mathrm{C}_{2} \mathrm{O}_{4}$ was also performed on the previously Kalling attacked surfaces.

\section{Results and discussion}

The evolution of the specific heat capacity of both steels with temperature is presented on Fig. 1 and compared with data from the literature [8,9]. It can be observed that Cp of P92 increases steadily with temperature till about $700^{\circ} \mathrm{C}$ (Fig. 1-a). Then, two spikes appear. The values are similar to those of the 9Cr-1Mo martensitic steel till $550^{\circ} \mathrm{C}$. However, the two peaks are slightly shifted with respect such study [9]. The first peak corresponds to the transition from ferromagnetic to paramagnetic at Curie's temperature. For steels of the same kind, this magnetic transition has already been observed by DSC around $745^{\circ} \mathrm{C}[8,10,11]$. The second peak can be related to the transformation from $\alpha$-phases (ferrite and martensite) to austenite $(\gamma)$.

Therefore, the potential evolution of the microstructure of P92 was investigated. Fig. 2 shows the P92 substrate before and after the Laser-Flash measurement till $900^{\circ} \mathrm{C}$. It is observed that the martensite phase rate (dark grey) and the ferrite phase (light grey) slightly decreased and that austenite grains (uncolored) were formed. Although a precise quantification of these phases could not be performed by image analyses with our tools, it clearly appears phase transformations occurred during the measurements. This can be related to partial austenitization [12] and dissolution of carbides typical of this steel at high temperatures [13]. Due to these transformations it is difficult to correctly define the heat capacity of ferritic-martensitic steels above $700^{\circ} \mathrm{C}$ by using this DSC technique. Thus, considering these variations, the conductivity values calculated beyond this point must be considered carefully.

(a)

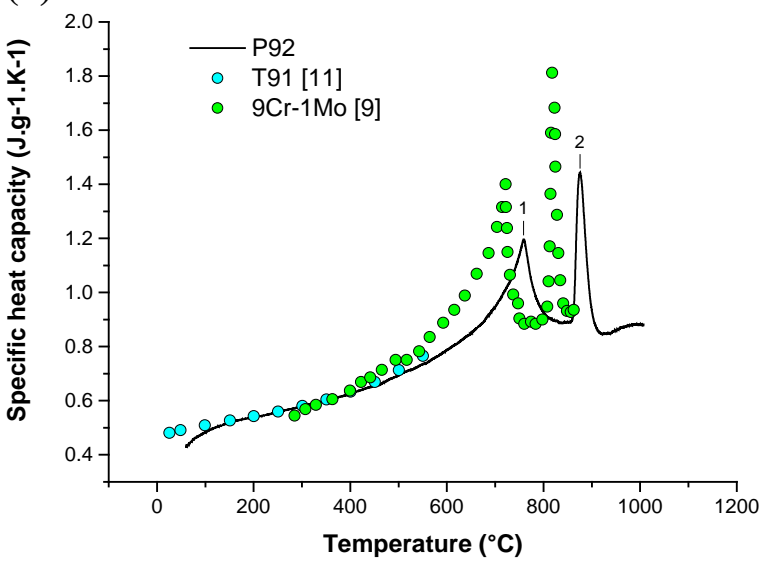

(b)

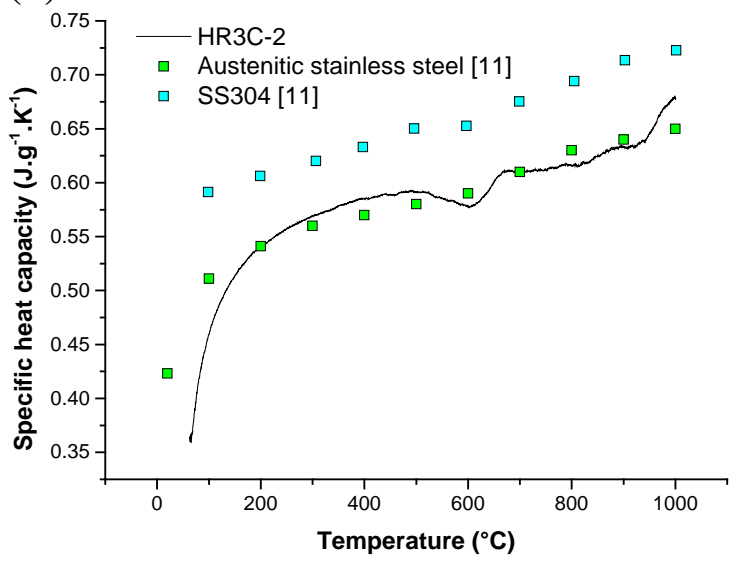

Fig. 1. Specific heat capacity $\left(C_{p}\right)$ measured via DSC for (a) P92 and (b) HR3C steels as a function of the temperature compared with literature data $[8,9]$. 

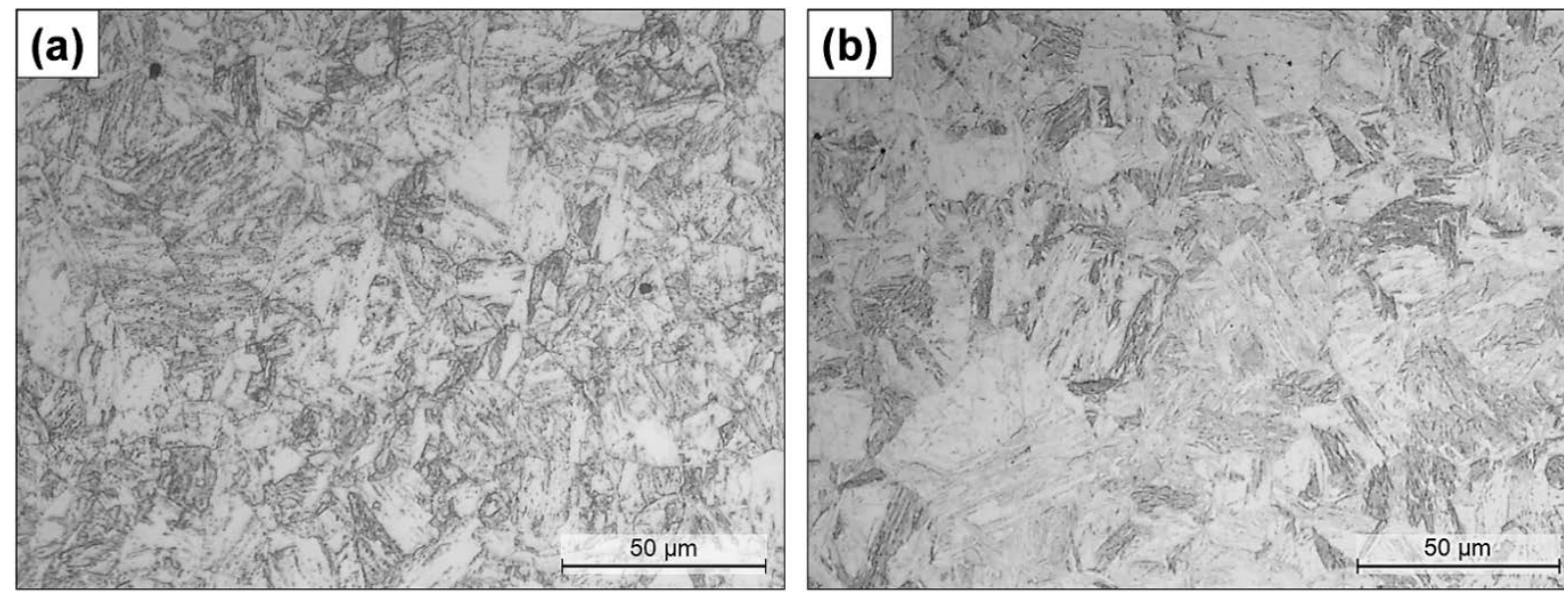

Fig. 2. Optical micrographs of the ferritic-martensitic P92 steel for (a) the initial substrate and (b) the substrate after the Laser-Flash analysis conducted till $900^{\circ} \mathrm{C}$. Etching was performed using Kalling's no. 2 reagent.

For HR3C steel, the trend of the $\mathrm{C}_{\mathrm{p}}$ evolution with temperature (Fig. 1-b) is similar to that of the other stainless steels. The sharp increase observed at low temperature is generally attributed to an issue related to temperature stability of the DSC signal during the early stages of the measurement but this does not affect the values of $C_{p}$ above $100^{\circ} \mathrm{C}$ [11]. Like with P92, the microstructures of H3RC were evaluated in the as-received and after the Laser-Flash measurement till $900^{\circ} \mathrm{C}$ (Fig. 3). The as-received material displays a very dissimilar grain size and many deformation twins in addition to a few dark spots related to $\mathrm{NbC}$ and to the onset of pitting from the metallographic attack. In contrast, annealing in the laser flash apparatus till $900^{\circ} \mathrm{C}$ resulted in annealing of the deformation twins, homogenization of the shape and size of the grains, the appearance of thermal twins and coarsening of carbides upon cooling [13]. Some spots related to the attack can also be observed.
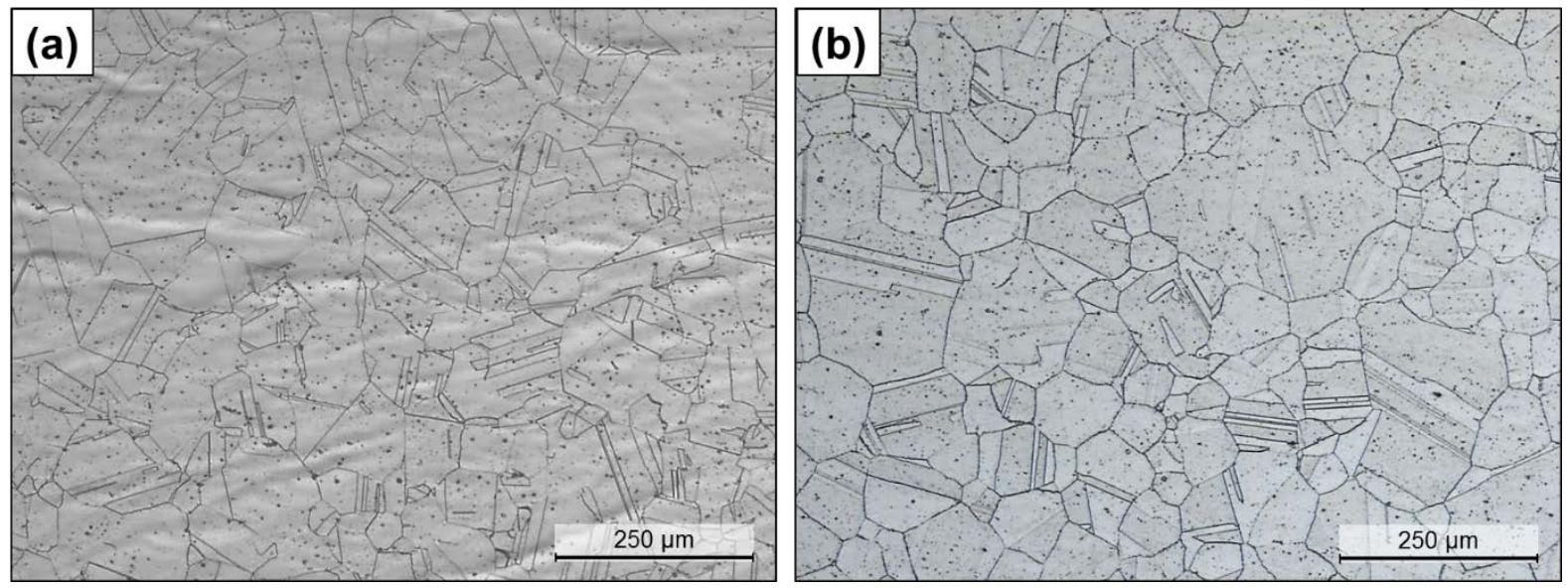

Fig. 3. Optical micrographs of the austenitic HR3C steel for (a) the initial substrate and (b) the substrate after the Laser-Flash analysis conducted till $900^{\circ} \mathrm{C}$. Etching was performed using Kalling’s no. reagent.

Fig. 4 shows the evolution of the density of P92 and HR3C steels with temperature till $1000^{\circ} \mathrm{C}$. As expected, the density decreases steadily with temperature in both steels till $800^{\circ} \mathrm{C}$. In the particular case of P92, a small change can be observed after the loss of its paramagnetic properties that results in a slight increase of its density. This change may also be associated with phase transformations related to the evolution of the ferrite $\alpha$-phase into the austenitic $\gamma$-phase above $840^{\circ} \mathrm{C}$ for P92 [8, 12].

The values of the CTE of P92 and HR3C calculated from the evolution of density room temperature till $1000^{\circ} \mathrm{C}$ are gathered in Table 1. The CTE values of P92 steel were compared with those of a P91 steel [4] as no values for P92 could be found in the literature. Both P91 and P92 are ferritic-martensitic steels but their minor differences in composition and microstructure are observed to result in a very different thermal expansion behavior. In contrast, the experimental values of CTE with temperature are very close to those provided by the manufacturer [3] till $800^{\circ} \mathrm{C}$. The increase of CTE at higher temperatures can be related to the dissolution of carbides [[13]]. 


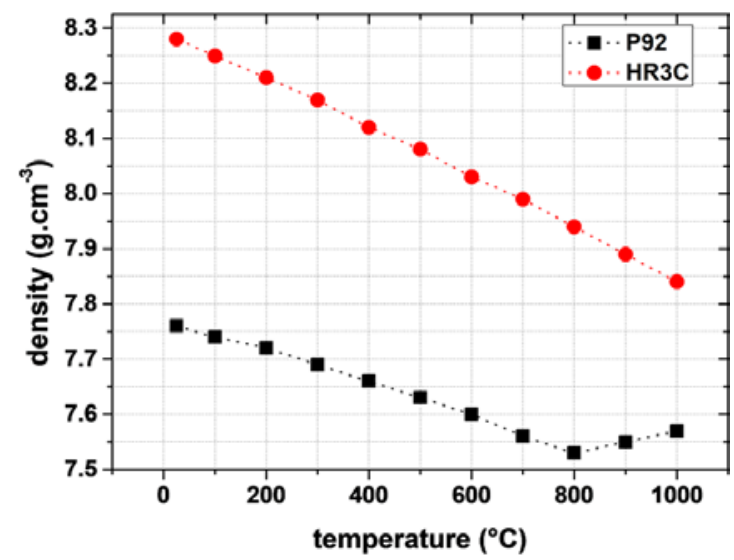

Fig.4. Evolution of density of P92 and HR3C with temperature.

Table 1. Calculated coefficients of thermal expansion (CTE) for P92 and HR3C as a function of the temperature.

\begin{tabular}{|c|c|c|c|c|c|c|c|c|c|c|c|c|}
\hline \multicolumn{2}{|c|}{ Temperature $\left({ }^{\circ} \mathrm{C}\right)$} & 25 & 100 & 200 & 300 & 400 & 500 & 600 & 700 & 800 & 900 & 1000 \\
\hline \multirow{4}{*}{$\begin{array}{l}\text { CTE } \\
\left(10^{-6} \cdot K^{-1}\right)\end{array}$} & P92 & - & 11.5 & 9.9 & 11.0 & 11.6 & 12.0 & 12.2 & 13.1 & 13.1 & 10.6 & 8.6 \\
\hline & & & & & $12.9 * *$ & $13.5^{* *}$ & $13.9 * *$ & $14.1^{* *}$ & & & & \\
\hline & HR3C & - & 16.2 & 16.2 & 16.3 & 17.4 & 17.5 & 17.9 & 17.9 & 18.4 & 18.8 & 19.2 \\
\hline & & & & & $16.9 *$ & $17.4^{*}$ & $17.2^{*}$ & $17.9 *$ & $18^{*}$ & $18.2^{*}$ & & \\
\hline
\end{tabular}

* reference of CTE for HR3C given by manufacturer [3], ** reference of CTE for P91 given by manufacturer [4]

Fig. 5 shows the thermal diffusivity values of P92 and HR3C steels as a function of the temperature. The HR3C austenitic steel presents a continuous increase of the thermal diffusivity with temperature. This result is in accordance with the fact that the heat conductivity of metals mainly depends on the electronic contribution of thermal conductivity, which is also proportional to the product of temperature and electrical conductivity. As temperature rises, the electron mobility increases, leading to greater heat transport rates. However, the P92 steel shows an interesting heat transport behavior with temperature. The thermal diffusivity decreases from room temperature to $700^{\circ} \mathrm{C}$ and then suddenly increases above $700^{\circ} \mathrm{C}$. This behavior could not be linked to phase transformation as the microstructure of the steel was not significantly modified by the high-temperature measurement (see Fig. 2). It rather appears to be likely related to the transition from ferromagnetic to paramagnetic property occurring at the Curie's temperature of the steel. It is believed that under the magnetic field, the electrons are not free to transfer heat through the metals and that the heat transport is mainly controlled by phonon conduction, which agrees with a decreasing tendency. Once the magnetic properties are lost, the electronic contribution of thermal conductivity becomes predominant again, thus explaining the rise in thermal diffusivity. Such thermal behavior of ferro-martensitic steel has already been reported in a previous study [5].

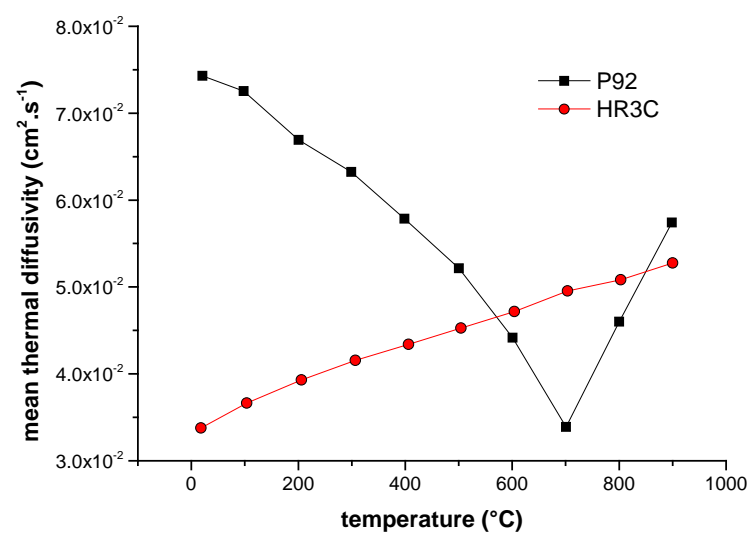

Fig. 5. Thermal diffusivity of P92 and HR3C steels as a function of the temperature.

Using the measured values of thermal diffusivity, density and specific heat as a function of temperature, thermal conductivity calculations have been performed and are presented in Fig. 6. In agreement with the data provided 
by the manufacturer of HR3C, the thermal conductivity for HR3C steel continuously increases with temperature [3]. In contrast, the thermal conductivity of P92 steel at room temperature is lower than the ones provided for P92 at $200^{\circ} \mathrm{C}$ and $400^{\circ} \mathrm{C}$ and for a similar ferritic-martensitic P91 steel [4]. This demonstrates the sensitivity of thermal conductivity to the chemical composition and metallurgical state of this metal substrate $[8,14]$. Between $25^{\circ} \mathrm{C}$ and $700^{\circ} \mathrm{C}$, the thermal conductivity of P92 appears relatively constant before it increases. This clearly indicates that the decrease in thermal diffusivity in the same temperature range is balanced by the increase of density and $\mathrm{C}_{\mathrm{p}}$. Although the values of thermal conductivity of $\mathrm{P} 92$ above $700^{\circ} \mathrm{C}$ may be uncertain, they are well above the values of HR3C, for which the thermal diffusivity, density and $C_{p}$ follow the same trend with temperature.

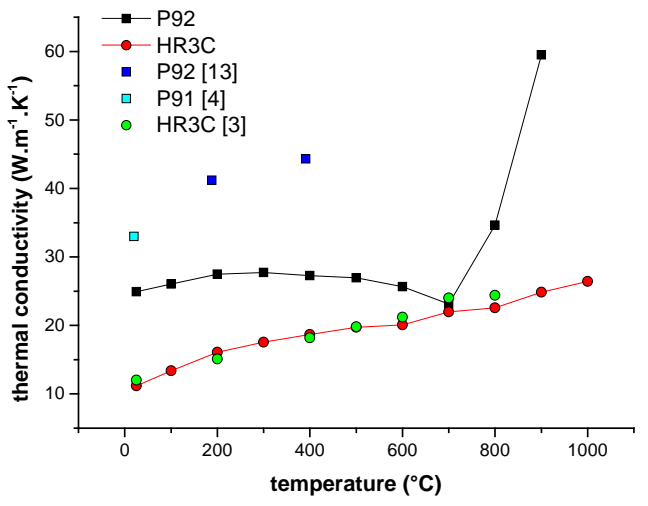

Fig. 6. Calculated thermal conductivity of P92 and HR3C steels as a function of the temperature and comparison with literature $[3,4,15]$.

\section{Conclusion}

In this study, the thermal conductivities of the ferritic-martensitic P92 steel and of the austenitic HR3C steel were calculated as a function of temperature using the measured values of thermal diffusivity, density and specific heat. The results indicated that the evolution of the thermal properties with the temperature were fundamentally different for these two steels due to their chemical compositions and structures. While the values of thermal diffusivity, density and heat capacity of HR3C linearly increase with temperature, the properties of P92 exhibited major changes around the temperature of its ferromagnetic transition around $700^{\circ} \mathrm{C}$. Despite these clear differences in thermal behavior, both P92 and HR3C steels present similar thermal conductivities on the range of temperature of interest for application in steam turbines.

\section{Acknowledgements}

The authors gratefully acknowledge European Union for the funding of FP7 project "POEMA: Production of Coatings for New Efficient and Clean Coal Power Plant Materials” (Grant agreement no. 310436).

\section{References}

[1] Holcomb GR. Steam oxidation and chromia evaporation in ultrasupercritical steam boilers and turbines. Journal of the Electrochemical Society. 2009;156(9):C292-C297.

[2] Viswanathan R. Materials technology for coal-fired power plants. Advanced Materials and Processes. 2004;162(8):73-80.

[3] Nippon Steel and Sumitomo Metal corp. HR3C material data sheet. http://www.tubular.nssmc.com/productservices/specialty-tube/product/hr3c/ [accessed 15 Jan 2018].

[4] ThyssenKrupp Materials International. P91/T91 Material data sheet. http://www.s-kh.com/media/de/Service/Werkstoffblaetter_englisch/Kesselrohre_ASTM/P91_T91_engl.pdf/ [accessed 15 Jan 2018].

[5] Boissonnet G, Boulesteix C, Bonnet G, Balmain J, Pedraza F. Thermal transport properties of new coatings on steels for supercritical steam power plants. Oxidation of Metals. 2017;88(1-2):191-202.

[6] Taylor RE, Wang X, Xu X. Thermophysical properties of thermal barrier coatings. Surface and Coatings Technology. 1999;120:89-95.

[7] ASTM E1461-11. Standard test method for thermal diffusivity by the flash method. 2011. 
[8] Jeyaganesh B, Raju S, Murugesan S, Mohandas E, Vijayalakshmi M. A study on the effect of thermal ageing on the specific-heat characteristics of $9 \mathrm{Cr}-1 \mathrm{Mo}-0.1 \mathrm{C}$ (mass\%) steel. International Journal of Thermophysics. 2009;30(2):619-634.

[9] INL. Developing and evaluating candidate materials for generation IV supercritical water reactors. [Technical report]. March 2006.

[10] Peitscha PR, Danón CA. Comparative study of 9\% Cr martensitic-ferritic steels using differential scanning calorimentry. Procedia Materials Science. 2015;9:514-522.

[11] Raju S, Ganesh BJ, Rai AK, Mythili R, Saroja S, Mohandas E, Vijayalakshmi M, Rao KB, Raj B. Measurement of transformation temperatures and specific heat capacity of tungsten added reduced activation ferritic-martensitic steel. Journal of Nuclear Materials. 2009;389(3):385-393.

[12] Ennis PJ, Zielińska-Lipiec A, Czyrska-Filemonowicz A. Influence of heat treatments on microstructural parameters and mechanical properties of P92 steel. Materials science and technology. 2000;16(10):1226-1233.

[13] Padilha AF, Rios PR. Decomposition of austenite in austenitic stainless steels. ISIJ International. 2002;42(4): 325-337

[14] Sklenička V, Kuchařová K, Král P, Kvapilová M, Svobodová M, Čmakal J. The effect of hot bending and thermal ageing on creep and microstructure evolution in thick-walled P92 steel pipe. Materials Science and Engineering: A. 2015;644:297-309.

[15] Steel Grades. P92 material data sheet. http://steel-grades.com/Steel-Grades/Structure-Steel/ASTM-A335GRADE-P92.html/ [accessed 15 Jan 2018].

(C) 2019 by the author(s). This work is licensed under a Creative Commons Attribution 4.0 International License (http://creativecommons.org/licenses/by/4.0/). Authors retain copyright of their work, with first publication rights granted to Tech Reviews Ltd. 